\title{
Mercados agroalimentares do Vale do Jaguari (RS): o caso das frutas,
}

\section{legumes e verduras (flv)}

\author{
Dutra, Eduardo Gilvan ${ }^{1,3}$; Sibele Vasconcelos de Oliveira ${ }^{1}$; Rita Inês Paetzhold Pauli'; \\ Gustavo Pinto da Silva ${ }^{2}$
}

${ }^{1}$ Departamento de Economia e Relações Internacionais - Universidade Federal de Santa Maria, Av. Roraima n ${ }^{\circ}$ 1000, Cidade Universitária, Bairro Camobi, Prédio 74-C. Santa Maria - RS/Brasil; ${ }^{2}$ Colégio Politécnico da Universidade Federal de Santa Maria, Av. Roraima no 1000, Cidade Universitária, Bairro Camobi, Colégio Politécnico. Santa Maria - RS/Brasil; ${ }^{3}$ eduardodutraeco@gmail.com

Dutra, Eduardo Gilvan; Sibele Vasconcelos de Oliveira; Rita Inês Paetzhold Pauli; Gustavo Pinto da Silva (2019) Mercados agroalimentares do Vale do Jaguari (RS): o caso das frutas, legumes e verduras (flv). Rev. Fac. Agron. Vol 118 (1): 147-159.

\begin{abstract}
A abertura comercial intensificada a partir da década de 1990, condicionou a internacionalização dos mercados. Por outro lado, as políticas públicas de compras institucionais de alimentos crescem, sobretudo após 2000, e juntamente com as novas demandas vem reconfigurando territórios e colocando em evidência teórico-prática os mercados. $\mathrm{O}$ artigo analisa os mercados de hortigranjeiros acessados por agricultores da região do Vale do Jaguari (RS), bem como as especificidades dos atores envolvidos, das unidades de produção e dos canais de comercialização presentes. Metodologicamente, utilizou-se o enfoque qualitativo e quantitativo, com aplicação de questionários junto a 179 fruticultores e 135 olericultores, além da análise de dados secundários. Dentre alguns resultados encontrados, destaca-se o envelhecimento da população rural, sendo a média de idade dos responsáveis pela produção de FLV de 52 anos. Soma-se a isso, o esvaziamento das propriedades, sendo que essas possuíam, em média, 3,2 residentes por propriedade. Quanto às especificidades dos mercados acessados pelos agricultores, constatou-se que as feiras são os principais acessados. Por fim, conclui-se que mesmo diante da competição dos atuais mercados agroalimentares, os mercados de proximidade predominam frente aos demais no Vale do Jaguari, seguido dos mercados locais e territoriais para as hortaliças e dos convencionais para as frutas.
\end{abstract}

Palavras-chave: Mercados agroalimentares; abastecimento alimentar; agronegócio.

Dutra, Eduardo Gilvan; Sibele Vasconcelos de Oliveira; Rita Inês Paetzhold Pauli; Gustavo Pinto da Silva (2019) Agrifood markets of the Vale do Jaguari (RS): the case of fruits, vegetables and viridity (fvv). Rev. Fac. Agron. Vol 118 (1): 147-159.

\begin{abstract}
The commercial opening, intensified after the 1990s, conditioned the internationalization of the markets. On the other hand, public policies for institutional food purchases have grown mainly after 2000, and toguether with the new demands, comes reconfiguring territories and placing theoretical and practical evidence on markets. The article analyzes the horticultural markets accessed by farmers in the Jaguari Valley region, as well as the specificities of the actors involved, the production units and the commercialization channels present. Methodologically, the qualitative and quantitative approach was applied, with questionnaires applied to 179 fruit growers, 135 farmers, in addition to the analysis of secondary data. Among the results found, the aging of the rural population stands out, being the average age of those responsible for the production of FLV of 52 years. In addition to this, the emptying of properties, which had, on average, 3.2 residents per property. As for the specific features of the markets accessed by farmers, it has been found that fairs are the main markets accessed by them, both for fruits and for vegetables. Finally, it is concluded that even in the face of the competition of the current agrifood markets, the proximity markets predominate in comparison with the others in the Jaguari Valley, followed by the local and territorial markets for vegetables and the conventional ones for fruits.
\end{abstract}

Keywords: Agrifood markets; food supply; agribusiness.

https://doi.org/10.24215/16699513e015

https://revistas.unlp.edu.ar/revagro

Recibido: $20 / 08 / 2018$

Aceptado: 3/05/2019

Disponible on line: 01/07/2019

ISSN 0041-8676 - ISSN (on line) 1669-9513, Facultad de Ciencias Agrarias y Forestales, UNLP, Argentina 


\section{INTRODUÇÃO}

No Brasil, o processo de globalização dos mercados agroalimentares iniciou a partir dos anos de $1990 \mathrm{com}$ a abertura comercial e a liberalização dos mercados de produtos agrícolas para o resto do mundo. Desde então, foi possível observar um intenso processo de concentração de capitais no setor agroalimentar (PerezCassarino \& Ferreira, 2013, Costa et. al., 2008, Wilkinson, 2004). Tais medidas abriram possibilidade para que grandes empresas supermercadistas e atacadistas de alimentos se instalassem no país e fizessem dos non-traditional food exports ${ }^{1}$ mercadorias essenciais para dominação de novos mercados (Wilkinson, 2004, Reardon et al., 2003).

Essas dominações passaram a distanciar produtores de alimentos dos consumidores, uma vez que as empresas globais tendem a criar suas próprias centrais de abastecimento privilegiando a compra de produtores especializados que, em grande parte, se encontram distantes das lojas onde os produtos são comercializados (Bonnano et al., 2017, Saitone \& Sexton, 2017). Além disso, as centrais de abastecimento (tais como a CEASA) também têm contribuído para um maior distanciamento entre agricultores e consumidores. Tal fato justifica-se por grande parte dos alimentos comercializados nessas centrais serem oriundos das mais diversas regiões do país e, em alguns casos, até de outros países (Cunha \& Belik, 2012). Para se ter ideia, desde o começo dos anos 2000 até o início da década de 2010, a comercialização de hortifrutigranjeiros pelas Ceasas teve um acréscimo de aproximadamente $7,8 \%$ (Cunha \& Belik, 2012).

Nesse sentido, estudiosos abandonam o entendimento dos mercados agroalimentares como sendo de concorrência perfeita e passam a compreendê-los como aqueles mais alinhados às economias industriais (onnano et al., 2017). Destarte, evidencia-se que os modernos sistemas de abastecimento, em geral, são organizados de tal forma que os alimentos percorrem longas distâncias em câmaras frias e que, muitas vezes, também são submetidos a outras tecnologias de conservação, como estabilizadores de matures (Coley et al., 2011). Esses recursos ao mesmo tempo em que possibilitam a oferta de uma gama de alimentos produzidos em regiões específicas para todo globo acabam por excluir agricultores que antes eram responsáveis por abastecer os mercados do seu entorno (Wilkinson, 2008).

Diante deste contexto, e considerando a existência de regiões tradicionalmente dependentes de alimentos de outras regiões questiona-se: dada a competitividade e a expansão do moderno sistema agroalimentar até mesmo nas regiões interioranas do país, como estão

\footnotetext{
${ }^{1}$ Para Wilkinson (2004, p.66), os non-traditional food exports, surgem concomitantemente com os foreign direct investment (FDI). Isso se dá em função da exportação desses alimentos para países da América Latina passar a ser visto como oportunidades de crescimento pelos países do norte, e então englobar a estratégia de crescimento baseado nas exportações (export-led growth). Tais alimentos são basicamente frutas e verduras (preferencialmente prépreparadas), e peixes.
}

operando os mercados agroalimentares acessados por agricultores que produzem frutas, legumes e verduras (FLV) atualmente?

Para responder a esse problema de pesquisa, foi escolhido o caso da região do Vale do Jaguari localizado geograficamente no centro-ocidental do Rio Grande do Sul. A região destacada abrange nove municípios, a saber: Santiago, Capão do Cipó, Unistalda, Nova Esperança do Sul, Jaguari, São Francisco de Assis, Cacequi, São Vicente do Sul e Mata. Essa delimitação se deu em razão do duplo aspecto encontrado na bibliografia existente sobre ela: de um lado, a dependência alimentar vivenciada por essa em relação a outras regiões (Dutra et al., 2017), de outro lado verifica-se a presença de algumas iniciativas de abastecimento localizado (Vendruscolo et al., 2016, Silva, 2016).

Destacam-se as frutas, legumes e verduras (FLV) comercializadas in natura ou processadas, sejam elas as produções de maior relevância para unidades de produção agrícola (UPA) ou como atividade complementar de geração de renda. Esses alimentos foram escolhidos como objetos de estudo tanto por se mostrarem garantidores de renda para muitas famílias de agricultores quanto por estabelecerem conexões e associações com as relações sociais envolvidas no processo produtivo local (Souza, 2009, Cunha, 2015).

Dessa forma, tem-se como objetivo geral analisar os mercados agroalimentares acessados por agricultores produtores de FLV do Vale do Jaguari (RS). Já como objetivos específicos pretende-se: a) analisar as especificidades dos mercados agroalimentares acessados por agricultores do Vale do Jaguari (RS); b) caracterizar os agricultores da região que atuam nos mercados de frutas, legumes e verduras; c) caracterizar o perfil de produção e comercialização de FLV disponibilizados por agricultores aos mercados da região do Vale do Jaguari (RS); e, d) avaliar os principais gargalos e potenciais da produção e comercialização de FLV disponibilizados pelos agricultores da região analisada.

Este estudo justifica-se pela importância que o conhecimento da produção local para as necessidades locais ocupa frente ao moderno sistema de abastecimento, mas também como forma racional de se pensar a vida econômica (Schumacher, 1983). Além do mais, tomando-se como bases algumas obras referências que retratam o papel fundamental da produção de alimentos para o desenvolvimento regional (Bowen, 2010, Wiskerke, 2009, Ploeg, 2008) nota-se que ainda existem lacunas teóricas na literatura acerca dessa problemática, motivo esse que inspira esta pesquisa.

Somando-se a essa breve introdução, este artigo divide-se em mais quatro seções. Na próxima serão feitas algumas considerações sobre especificidades dos mercados agroalimentares que vão além do entendimento tradicional das "forças" de oferta e demanda. Em uma terceira seção, serão apresentados os métodos utilizados na pesquisa. No quarto tópico os principais resultados da pesquisa serão demonstrados, sendo esse seguido de algumas considerações finais. 


\section{Especificidades dos mercados agroalimentares}

Um dos principais problemas vivenciados pelos agricultores produtores de alimentos na atualidade, e, principalmente aqueles que utilizam menor escala produtiva, é que os mercados que eles acessam geralmente não são visíveis e reconhecidos pelo poder público e sociedade em geral. As suas modalidades são muitas e não se limitam simplesmente as relações do sistema de preços, preferências, oferta, demanda e equilíbrios gerados automaticamente (CMS, 2017).

Nesse sentido, alguns autores vêm desenvolvendo tipologias para classificar esses mercados, e com maior atenção para aqueles acessados por agricultores familiares (Ploeg, 2006, Wilkinson, 2008, Schneider, 2016). Apesar da relevância dos estudos de Ploeg (2006) e Wilkinson (2008) no debate dos mercados, nesta pesquisa optou-se por utilizar a tipologia proposta por Schneider (2016), devido a esse autor enfatizar de forma detalhada as dinâmicas de interação e processos de diferenciação social dos agricultores familiares, o que se aproxima mais das intenções propostas neste trabalho.

Schneider (2016) propôs uma tipologia que compreende três aspectos principais, a saber: a) o mercado como um locus, uma delimitação espacial, onde se realizam trocas materiais de produtos $\mathrm{e}$ mercadorias; b) o mercado como ordenador da sociedade e da economia, tal qual se desenvolve no capitalismo; e, c) o mercado como uma construção social, resultante do contato e interações que ocorrem entre os agentes que trocam e intercambiam por diferentes motivos, podendo ser econômicos, sociais ou culturais. A tipologia proposta pelo autor classifica os mercados acessados pela agricultura familiar em quatro modalidades distintas, sendo elas: mercados de proximidade; mercados locais e territoriais; mercados convencionais; e, mercados públicos e institucionais. Além disso, a cada modalidade de mercado o autor classifica o tipo de agricultor familiar, o alcance espacial desses mercados, a natureza das trocas, suas formas de regulação e os canais de comercialização, como demonstra na tabela 1 a seguir.

Tabela 1. Tipologia dos mercados da agricultura familiar. Fonte: Retirado de Schneider (2016, p. 127).

\begin{tabular}{|c|c|c|c|c|c|}
\hline & $\begin{array}{l}\text { Tipo de } \\
\text { agricultor } \\
\text { familiar }\end{array}$ & $\begin{array}{l}\text { Locus el } \\
\text { ou alcance } \\
\text { espacial }\end{array}$ & $\begin{array}{c}\text { Natureza das } \\
\text { trocas/ } \\
\text { modelo de } \\
\text { negócios }\end{array}$ & $\begin{array}{l}\text { Forma de } \\
\text { regulação }\end{array}$ & $\begin{array}{c}\text { Canais de } \\
\text { comercialização }\end{array}$ \\
\hline $\begin{array}{l}\text { Mercados de } \\
\text { proximidade }\end{array}$ & $\begin{array}{l}\text { Camponês; } \\
\text { Produtor de } \\
\text { excedentes }\end{array}$ & $\begin{array}{c}\text { Spot; } \\
\text { Venda Direta; } \\
\text { Somente Local }\end{array}$ & $\begin{array}{c}\text { Interpessoal } \\
+ \\
\text { Solidário }\end{array}$ & $\begin{array}{c}\text { Confiança } \\
+ \\
\text { Amizade }\end{array}$ & $\begin{array}{l}\text {-Na propriedade } \\
\text { (colhe-pague); } \\
\text {-No domicilio/casa; } \\
\text {-Beira da estrada; } \\
\text {-Entrega direta; } \\
\text {-Feira local; } \\
\text {-Grupos Consumo }\end{array}$ \\
\hline $\begin{array}{l}\text { Mercados } \\
\text { locais e } \\
\text { territoriais }\end{array}$ & $\begin{array}{l}\text { Agricultor } \\
\text { familiar; } \\
\text { Produtor } \\
\text { simples de } \\
\text { mercadorias }\end{array}$ & $\begin{array}{c}\text { Spot; } \\
\text { Local, regional e } \\
\text { territorial }\end{array}$ & $\begin{array}{c}\text { Diversificado } \\
+ \\
\text { Complementaridade }\end{array}$ & $\begin{array}{c}\text { Reputação/ } \\
\text { Confiança } \\
+ \\
\text { Procedência } \\
+ \\
\text { Preços }\end{array}$ & $\begin{array}{c}\text {-Feira regional; } \\
\text {-Feira nacional; } \\
\text {-Redes de Venda; } \\
\text {-Eventos; } \\
\text {-Loja especializada; } \\
\text {-Restaurantes; } \\
\text {-Associação vendas; } \\
\text {-Sacolão. }\end{array}$ \\
\hline $\begin{array}{c}\text { Mercados } \\
\text { convencionais }\end{array}$ & $\begin{array}{l}\text { Produtor de } \\
\text { mercadorias }\end{array}$ & $\begin{array}{c}\text { Sem lugar } \\
\text { definido; } \\
\text { Placeless/Unbond }\end{array}$ & Concorrencial & $\begin{array}{c}\text { Contratos } \\
+ \\
\text { Preços }\end{array}$ & $\begin{array}{c}\text {-Atravessadores; } \\
\text {-Cooperativa; } \\
\text {-Agroindústria; } \\
\text {-Empresa privada; } \\
\text {-Internet; } \\
\text {-Supermercados }\end{array}$ \\
\hline $\begin{array}{l}\text { Mercados } \\
\text { públicos e } \\
\text { institucionais }\end{array}$ & $\begin{array}{l}\text { Todos os } \\
\text { tipos de } \\
\text { fornecedores }\end{array}$ & Multiespacial & $\begin{array}{c}\text { Licitatório, Seleção } \\
\text { Pública }\end{array}$ & $\begin{array}{l}\text { Contratos } \\
\text { públicos } \\
+ \\
\text { Leis }\end{array}$ & $\begin{array}{c}\text {-Alimentação Escolar; } \\
\text {-Fair trade; } \\
\text {-Órgãos internacionais } \\
\text { (FAO; PMA); } \\
\text {-ONGs; } \\
\text {-Hospitais, } \\
\text { Universidades, Forças } \\
\text { Armadas; } \\
\text {-Entidade Assistencial; } \\
\text {-Estoques governo }\end{array}$ \\
\hline
\end{tabular}


A caracterização dos mercados sumarizados no Quadro 1, pode ser explicitado como segue (Schneider, 2016, p. 127).

I) Mercados de proximidade: predominam relações de troca interpessoais, onde suas ações se dão pelas relações de parentesco existentes, interconhecimento e reciprocidade, onde há uma valorização da qualidade dos bens trocados, mais do que o próprio lucro. Nesta modalidade, a atuação dos mercados se dá na forma de trocas diretas, valorizando a autogestão e a subsidiariedade. Os agricultores que atuam nestes mercados possuem certo grau de autonomia relativa, tanto pelos recursos que possuem, quanto pela natureza das relações que estabelecem nas trocas. No que diz respeito aos mecanismos de circulação e distribuição de produtos e mercadorias transacionados, esses buscam o deslocamento físico mais restrito possível, preferindo então, que sejam realizados "on spot" (no local) (Schneider, 2016, p. 123).

II) Mercados locais e territoriais: as relações de troca já passam a ser monetizadas, aproximando-se cada vez mais dos mercados convencionais de oferta e demanda, assim como, critérios e indicadores quantitativos. Ainda que alguns aspectos relacionados a valores que fazem parte dos mercados anteriormente descritos persistam nesta modalidade, aqui a produção já se dá com o objetivo específico de venda ou troca para ganhar, configurando-se como uma economia mercantil simples. O principal aspecto distintivo que surge em relação aos mercados de proximidade, é que agora a distribuição e circulação dos produtos e mercadorias deixam de ser feito diretamente por quem produz, e passa existir um intermediário (brocker, atravessador) com interesses e custos, lançando mão de mecanismo de controle e regulação para manter seu poder. Isso se manifesta por meio da certificação de produtos, preços diferenciados segundo a regularidade da oferta, entre outros (Schneider, 2016, p. 123-124). Nos mercados locais e territoriais, ainda que se mantenha um locus ligado a determinados espaços, o seu local de atuação e seus canais de comercialização não se restringem mais somente a este local. Manifestam-se movimentos de abrangência para fora de um lugar delimitado, muitas vezes, surgindo nichos específicos.

III) Mercados convencionais: as características que os subjazem são as de uma economia de livre mercado. Aqui, os produtos, bens e mercadorias se orientam pela oferta e demanda, sob comando de influentes agentes privados que comercializam em vários níveis e modos, com objetivos de venda e compra e vice-versa. Diferente dos mercados territoriais, aqui se dispensa um locus físico, configurando-se como mercados placeless (sem lugar). O que norteia a distribuição e circulação de mercadorias nestes são a busca do lucro, onde haja a máxima atuação da oferta e da demanda, seja elas em mercados nacionais ou como internacionais. Também caracterizam esses mercados, os altos riscos e as incertezas que os rodeiam, surgindo, por tanto, o difícil controle e regulação. A busca dessa regulação se dá basicamente por conta de complexos contratos de representação, acordos de uso de marcas e direitos de propriedade e regulamentação de ganhos (Schneider, 2016, p. 123).
IV) Mercados públicos e institucionais: este último tipo de mercado abordado pelo autor, e que no Brasil nos últimos anos os agricultores familiares têm se inserido de forma crescente, são espaços de troca onde o agente principal passa a ser o Estado, algum organismo público, ou organização pública, como exemplo, aquelas que praticam o comércio justo (fair trade). Mesmo sendo mercados que funcionam com alto grau de regulamentação e controle formal (leis e regras, esses devendo ser entendidos como mecanismos ordenadores), tais mercados possuem a peculiaridade de serem fortemente dirigidos pela demanda (demand driven). Os mercados públicos mostram-se como muito atraentes para os produtos e mercadorias dos agricultores familiares, uma vez que os preços pagos pela demanda dirigida tendem a ser superiores daqueles pagos pelos mercados convencionais. Schneider (2016, p. 124) chama atenção que "[...] Mais do que qualquer outro, os mercados públicos são efetivamente o resultado de construção social e política, pois lidam com fundos públicos que se originam de contribuições públicas, razão pela qual requerem mecanismos de governança abertos e democrático". Esses mercados não possuem um locus ou espaço específico, e, em geral, são criados para atender certas demandas, como da alimentação escolar, hospitais, casas de repouso etc.

\section{METODOLOGIA}

Para esta pesquisa foi delimitado os agricultores inseridos na região do Vale do Jaguari, a qual possui uma área total de $11.254,1 \mathrm{~km}^{2}$ (FEE, 2015), população total de 117.084 habitantes (FEE, 2016) e densidade demográfica de 10,4 hab/ $\mathrm{km}^{2}$. Para muitos autores, o Vale do Jaguari possui uma localização estratégica para diversos fins (Brasil, 2016, Uberti, 2012). No passado, por ocupar um espaço de fácil deslocamento de tropas militares para os conflitos de posse de terras nas várias extremidades do estado, além de ser passagem de muitos tropeiros (condutores de bovinos). No presente, por de certa forma, estar entre o Rio Grande do Sul desenvolvido e o "atrasado" (Uberti, 2012, p. 5), o que pode ser estratégico do ponto de vista de novas oportunidades.

No entanto, estudos recentes alegam que sua economia não se mostra muito competitiva e diversificada frente a outras regiões do estado (Bertê et al., 2016, Silva \& Anése, 2011, Anése, 2009, Ilha \& Molinari, 2008). Para os produtos agrícolas existem dificuldades de agregação de valor, obstáculos para certificação e limites de comercialização (Bertê et al., 2016, Silva \& Anése, 2011, Anése, 2009, Ilha \& Molinari, 2008). Por outro lado, destacam-se alguns fatores positivos tais como organizações cooperativistas de sucesso como a Associação dos Produtores de Vinho e Derivados de Uva do Vale do Jaguari, Associação dos Produtores de Batata-Doce de São Vicente do Sul, Cooperativa Santiaguense da Agricultura Familiar Ltda, entre outros.

Do ponto de vista metodológico a presente pesquisa é classificada como exploratória. Nesse sentido, considerando a importância da temática dos mercados agroalimentares tanto na literatura nacional (Schneider 
et al., 2016, Niederle, 2016, Grisa et al., 2011, Agne \& Waquil, 2011, Wilkinson, 2008, Maluf, 2004) como também na internacional (CMS, 2017, Thorsoe \& Noe, 2016, Ploeg et al., 2012, Sonnino \& Marsden, 2006, Kirwan, 2004), este estudo visa buscar elementos da literatura existente e explorar uma região ainda pouco estudada.

Quanto ao enfoque da pesquisa, essa se classifica como qualitativa e quantitativa. Nesse sentido, para se ter um panorama mais profundo, intenso e holístico do fenômeno a ser estudado optou-se pelo inquirimento direto via questionário semiestruturado, ora nas próprias unidades de produção agrícola, ora nos próprios locais de comercialização.

A metodologia para coleta de dados se deu em duas etapas, sendo uma primeira com o levantamento e identificação dos agricultores produtores de FLV junto à extensionistas da Associação Riograndense de Empreendimentos de Assistência Técnica e Extensão Rural / Associação Sulina de Crédito e Assistência Rural (EMATER-RS/ASCAR), e uma segunda a pesquisa de campo propriamente dita. Aqui vale ressaltar, que a identificação de agricultores ocorreu no ano de 2015, mas com atualizações no decorrer da pesquisa. Essas atualizações se deram com conversas informais com representantes dos Sindicatos dos Trabalhadores Rurais, cooperativas da região, e com os próprios agricultores que informavam sobre a existência uns dos outros.

As saídas de campo, com exceção de Santiago que foi no mês de dezembro de 2016, ocorreram nos meses de setembro e outubro de 2017 , devido a disponibilidade de recursos das instituições fomentadoras. Anterior ao deslocamento, equipes foram montadas e treinadas por extensionistas rurais, a fim de instruir e estabelecer familiaridade dos mesmos com o questionário a ser utilizado. Ao todo, foram entrevistados 245 agricultores $^{2}$ (Santiago, Jaguari, Nova Esperança do Sul, São Francisco de Assis, Cacequi, São Vicente do Sul, Mata) $)^{3}$, sendo que desses 135 se declararam olericultores, 179 fruticultores e 69 olericultores e fruticultores concomitantemente.

O grupo de entrevistados faz parte de uma amostragem por tipicidade, ou seja, trata-se de uma amostra não probabilística, selecionada via informações disponíveis (identificação junto a extensionistas da EMATER/ASCAR) de uma população conhecida, e que pode ser considerada representativa de toda população (Gil, 2009). Estima-se que atualmente 300 agricultores no Vale do Jaguari ocupam-se com a fruticultura e olericultura, sendo que mais de $81 \%$ desses foi entrevistado.

Concluída a etapa de coleta, esses foram analisados com auxílio do software Statistical Package for Social Sciences (SPSS Statistics) 20 mediante descrição dos

\footnotetext{
${ }^{2}$ Aqui, vale ser ressalvado, que a soma de fruticultores e olericultores é maior que o valor total de entrevistados, devido aos 69 agricultores que se declararam tanto olericultores quanto fruticultores.

3 Por limitação de tempo e recursos, optou-se por não entrevistar agricultores dos municípios de Capão do Cipó e Unistalda. A decisão em relação a esses dois municípios se deu por os mesmos possuírem pouco vínculo com atividades de produção de FLV, como relatado pelos próprios extensionistas da EMATER/ASCAR.
}

dados. Esse método foi utilizado por de adequar ao proposto na pesquisa, uma vez que Gil (2009) destaca que a descrição de dados permite caracterizar o que é típico de um grupo, indicar a variabilidade dos indivíduos e sua distribuição em relação a determinadas variáveis.

Por fim, vale destacar que também foram utilizados dados secundários nesta pesquisa. Esses tiveram significativa importância, principalmente, por servirem de base para maior entendimento acerca das características próprias do Vale do Jaguari. As principais fontes de extração desses quantitativos foram o Instituto Brasileiro de Geografia e Estatística (IBGE) e Fundação de Economia e Estatística (FEE).

\section{ANÁLISE E DISCUSSÃO DOS RESULTADOS}

Igumas características intrínsecas aos núcleos familiares, características dos estabelecimentos rurais, bem como o modo de produção dos agricultores produtores de FLV mostram-se instigantes. Para que se estabeleça esse debate, foi elaborada esta seção, que se subdivide em quatro seções secundárias. A primeira visa caracterizar os protagonistas da produção de FLV do Vale do Jaguari, ou seja, os agricultores. A seção secundária será destinada para destacar informações acerca das particularidades da produção em si, tais como as motivações que levaram os agricultores iniciar na fruticultura e na olericultura, bem como o ano desse começo. Além disso, ainda na mesma seção, são apresentadas informações quanto ao tamanho das propriedades, a importância que essas atividades representam na renda das propriedades e os principais gargalos enfrentados pelos agricultores para que esses atuem nesse tipo de produção. Por fim, na última subseção, elencam-se os principais mercados acessados por esses agricultores, junto a uma adaptação à proposição teórica de Schneider (2016) no que se refere aos mercados acessados pelos agricultores inquiridos neste estudo.

\section{Caracterização dos agricultores produtores de flv do vale do jaguari (rs)}

Segundo o Censo Agropecuário (2006), o número de estabelecimentos agropecuários ocupados por agricultores familiares, no Vale do Jaguari, era de 7.944 em posse de uma área de 208.445 hectares (IBGE, 2006). Para o caso específico de olericultores e fruticultores não foram encontrados dados individualizados, fato esse que motivou tal apuração com 245 agricultores ${ }^{4}$ (estabelecimentos rurais) com fins de complementação das informações disponíveis. Desses, 135 se declararam olericultores, 179 fruticultores e 69 praticantes tanto da olericultura quanto da fruticultura.

No que diz respeito ao número de pessoas que constituem o núcleo familiar dos entrevistados obtevese uma média de 3,2 pessoas por estabelecimento rural, sendo que em $30,2 \%$ dos domicílios residiam três

\footnotetext{
${ }^{4}$ Aqui, vale ser ressalvado, que a soma de fruticultores e olericultores é maior que o valor total de entrevistados, devido aos 69 agricultores que se declararam tanto olericultores quanto fruticultores.
} 
pessoas, $24,9 \%$ dos estabelecimentos residem duas pessoas e em $22,4 \%$ dos estabelecimentos residem quatro pessoas, como demonstra a tabela 2 .

Tabela 2. Número de pessoas que constituem o núcleo familiar dos estabelecimentos produtores de FLV do Vale do Jaguari (2017). Fonte: Elaborado pelo autor com base nos dados primários (2017).

\begin{tabular}{ccc}
\hline $\begin{array}{c}\mathbf{N}^{\circ} \text { de residentes por } \\
\text { domicílio }\end{array}$ & $\begin{array}{c}\text { Frequência } \\
(\mathbf{n})\end{array}$ & $\begin{array}{c}\text { Percentual } \\
(\mathbf{\%})\end{array}$ \\
\hline 1,0 & 18 & 7,3 \\
2,0 & 61 & 24,9 \\
3,0 & 74 & 30,2 \\
4,0 & 55 & 22,4 \\
5,0 & 24 & 9,8 \\
6,0 & 8 & 3,3 \\
7,0 & 5 & 2,0 \\
\hline Total & 245 & 100,0 \\
\hline
\end{tabular}

O conjunto de pessoas que constituíam os núcleos familiares dos agricultores entrevistados soma 785 indivíduos, sendo que desses 413 (52,6\%) eram homens e 372 mulheres $(47,4 \%)$. Aqui vale ser destacada a semelhança dos dados coletados com os apresentados no Censo Demográfico 2010 (IBGE, 2010), já que esses informavam que da população rural do Vale do Jaguari, $53,1 \%$ era constituído por homens e $46,9 \%$ por mulheres.

Com relação à distribuição de idade dos agricultores responsáveis pela propriedade, constata-se que a maior parte desses está entre as faixas 51 e 60 anos $(37,6 \%)$ e 41 e 50 anos (22\%), ou seja, mais de $59 \%$ dos entrevistados possuem idade superior a 40 anos. Esses dados mostram-se preocupantes, uma vez que além do elevado êxodo rural observado a partir dos anos de 1950 (fruto da modernização conservadora da agricultura junto ao acelerado processo de industrialização do país), o fenômeno do envelhecimento no campo deixou de ser uma preocupação exclusivamente europeia e também passou a ser vivenciada pela população rural brasileira. Froehlich et al. (2011), em estudo referente à população rural da região central do Rio Grande do Sul evidenciaram o fenômeno de redução das taxas de natalidade como outro motivador da predominância de pessoas com maior idade no campo. Em décadas passadas, mesmo que o êxodo rural se mostrasse persistente as elevadas taxas de natalidade acabavam por amenizar o envelhecimento na zona rural (Froehlich et al., 2011, Morais, 2007).

\section{Particularidades da produção de flv da região}

O início da produção de FLV no Vale do Jaguari está intimamente vinculado à colonização, principalmente de italianos e alemães nos municípios que o constituem (Cesar, 1979, Lazzarotto, 1976, Roche, 1969). Por outro lado, quando considerada a recente urbanização dessas cidades (principalmente a partir da década de 50 ), constata-se a incipiência da constituição dos mercados agroalimentares $\mathrm{e}$, por conseguinte, da produção de FLV com finalidade comercial nesses municípios.

Conforme declarado pelos agricultores, verificou-se que pelo menos $84 \%$ dos fruticultores e $90,3 \%$ dos olericultores começaram sua produção com objetivo comercial a partir da década de 80 (tabela 3).

$\mathrm{Na}$ verdade, já havia comércio incipiente de hortifrutigranjeiros anterior ao período descrito, porém destaca-se que a sistematicidade na busca do comércio de alimentos é recente. ${ }^{5}$ Com relação às motivações que implicaram nas decisões iniciais de plantio de FLV no Vale do Jaguari, para $58,4 \%$ dos agricultores, o motivo principal está relacionado à oportunidade de ampliação de renda e para $38,4 \%$ decorreria desta se apresentar como uma atividade já praticada pelos seus ascendentes. $^{6}$

Quanto a atual estrutura fundiária das propriedades produtoras de FLV do Vale do Jaguari verificou-se que $63,3 \%$ apresentam até 25 ha, e $22 \%$ de 25,1 até 50 ha, o que explica a concentração da pesquisa dirigir-se ao público alvo pertencente a estes estratos. O trabalho nos cultivos das propriedades foi realizado por 518 pessoas oriundas dos núcleos familiares, e 11.420 diárias anuais de trabalho com mão de obra terceirizada (eventual) e, 40 empregos com carteira assinada.

Os dados do Censo Agropecuário de 2006 mostram que os estabelecimentos familiares possuíam em média 18,37 ha, enquanto os não familiares 309,18 hectares. Do total das propriedades rurais, a agricultura familiar representava $84,4 \%$, e os não familiares $15,6 \%$, estando esses últimos sob posse de $75,7 \%$ das áreas ocupadas (IBGE, 2006). O tamanho das propriedades rurais no Rio Grande do Sul pode ser considerado heterogêneo, diferindo-se de uma região para outra e coexistindo regiões com baixa e elevada concentração fundiária (Giovanini et al., 2011, Alves, Silveira, 2008). Quanto à composição da renda dos estabelecimentos rurais pesquisados, os dados demonstram que a fruticultura, para a região como um todo, tem maior importância que a olericultura. Para $31,1 \%$ dos fruticultores entrevistados, a atividade representa mais que $61 \%$ da receita da propriedade, enquanto que para os olericultores esse valor não chega a $21 \%$, como demonstra a tabela 4.

Vale destacar que a expressividade da fruticultura não se dá em todos os municípios do Vale do Jaguari. Em Mata, $50 \%$ dos fruticultores entrevistados relataram que essa produção representa menos que $20 \%$ da renda da propriedade.

\footnotetext{
${ }^{5}$ Alguns estudos já demonstravam a existência de comércio de FLV em períodos anteriores à década de 1980, tal como as práticas de quitanda em Santiago (SILVA, 2016), o comércio de saladas no povoado que surgia onde hoje é São Francisco de Assis (SANGOI, 2006), ou até mesmo práticas de escambo em Jaguari (PAULA, 1999) com a chegada dos colonizadores. 6 Esses resultados corroboram as afirmações dos entrevistados, na pergunta que se referia à contemporaneidade no início dessas atividades com finalidade comercial, além de mostrar que tanto a olericultura quanto a fruticultura têm se mostrado como uma alternativa de formação de renda no campo, apesar de nem sempre se constituir à renda principal das propriedades.
} 
Tabela 3. Frequência de agricultores do Vale do Jaguari que iniciaram na fruticultura e olericultura com fins comerciais por classe de anos. Fonte: Elaborado pelo autor com base nos dados primários (2017).

\begin{tabular}{lcccc}
\hline & \multicolumn{2}{c}{ Fruticultura } & \multicolumn{2}{c}{ Olericultura } \\
\cline { 2 - 5 } & Frequência (n) & Percentual (\%) & Frequência (n) & Percentual (\%) \\
\hline Anterior a 1950 & 11,00 & 6,15 & 1,00 & 0,74 \\
1951 até 1960 & 3,00 & 1,68 & 2,00 & 1,48 \\
1961 até 1970 & 5,00 & 2,79 & 2,00 & 1,48 \\
1971 até 1980 & 9,00 & 5,03 & 8,00 & 5,93 \\
1981 até 1990 & 18,00 & 10,06 & 15,00 & 11,11 \\
1991 até 2000 & 53,00 & 29,61 & 39,00 & 28,89 \\
2001 até 2010 & 60,00 & 33,52 & 29,00 & 21,48 \\
posterior a 2011 & 20,00 & 11,17 & 39,00 & 28,89 \\
\hline Total & 179,00 & 100,00 & 135,00 & 100,00 \\
\hline
\end{tabular}

Tabela 4. Representatividade da fruticultura e da olericultura na composição da renda total dos estabelecimentos rurais do Vale do Jaguari. Fonte: Elaborado pelo autor com base nos dados primários (2017).

\begin{tabular}{lcccc}
\hline & \multicolumn{2}{c}{ Olericultura } & \multicolumn{2}{c}{ Fruticultura } \\
\cline { 2 - 5 } & Frequência (n) & Percentual (\%) & Frequência (n) & Percentual (\%) \\
\hline Até $20 \%$ & 76 & 42,5 & 41 & 30,4 \\
$21-40 \%$ & 45 & 25,1 & 25 & 18,5 \\
$41-60 \%$ & 22 & 12,3 & 27 & 20 \\
$61-80 \%$ & 22 & 12,3 & 14 & 10,4 \\
Mais de $81 \%$ & 14 & 7,8 & 28 & 20,7 \\
\hline Total & 179 & 100 & 135 & 100 \\
\hline
\end{tabular}

No caso de Nova Esperança do Sul, 81,25\% responderam que fruticultura representa menos que $40 \%$ da renda da propriedade. Em Santiago, 61,29\% dos respondentes elencaram à produção de frutas importância inferior a $20 \%$ para os ganhos de seus estabelecimentos e em São Vicente do Sul 57,14\% relataram que tal atividade altera também em no máximo $20 \%$ na renda da propriedade.

Quanto à olericultura, apenas $20,1 \%$ dos entrevistados elencaram que essa contribua com mais de $61 \%$ da receita dos estabelecimentos rurais. Quando analisados os municípios de maneira individualizada, os resultados não se mostram muito diferente. Todavia, em Mata para $40,0 \%$ dos olericultores tal atividade altera a renda da propriedade em mais de $81 \%$. Para o caso de São Francisco de Assis e Santiago, 33,3\% e 29,5\% dos olericultores, respectivamente, também afirmaram que a atividade altera em mais de $81 \%$ a renda da propriedade.

Em outra perspectiva, observa-se que várias foram as mudanças que afetaram os sistemas agroalimentares nas últimas décadas, entre elas fatores relacionados a transnacionalização e concentração do abastecimento em atores específicos. Nesse sentido, dificuldades foram criadas para agricultores que produzem alimentos em pequena escala se inserirem nessa nova dinâmica de abastecimento. Sobretudo, citam-se as questões de quantidade, homogeneidade dos alimentos, rastreabilidade e competição com produtos oriundos de outros países (Craviotti, 2013, Marsden \& Cavalcanti, 2001).
No entanto, fatores como a má conservação das estradas na zona rural, falta de apoio governamental, poucos cursos de capacitação, entre outras mazelas inerentes a produção e ao comércio, também acabam por afetar a permanência de agricultores nas atividades de fruticultura e olericultura de pequena escala. Nesta pesquisa, quando questionados sobre a ocorrência ou não de uma série de problemas relacionados à produção e ao comércio, as respostas com maior assertivas positivas foram: intempéries (53,88\%), incidência de praga e doenças $(48,57 \%)$, e, falta de apoio governamental $(39,18 \%)$.

Apesar de problemas recorrentes que obstam uma maior eficiência produtiva e comercial, verificam-se especificidades tais como: a) no município de Cacequi, $61,5 \%$ dos entrevistados responderam vivenciar a má conservação das estradas e $57,7 \%$ com alto índice de incidência de doenças, pragas e ervas daninhas; b) em Jaguari, $62,9 \%$ relataram a alta frequência de intempéries e também com essa mesma percentagem, sofrer com resquícios de venenos das lavouras de monocultura $^{7}$; c) em Mata, 66,7\% responderam ter

${ }^{7} 62,9 \%$ dos agricultores do município de Jaguari relataram estar sofrendo com a larga escala de agroquímicos utilizados nas plantações de soja do município. Segundo eles, os defensivos ficam suspensos no ar e acabam atingindo outras lavouras que não apenas o seu alvo, e, então, as de videiras do município. Nesse sentido, em 10 de julho de 2017, foi aprovada em assembleia ordinária na Câmara Municipal de Vereadores de Jaguari, o Projeto de Lei $n^{\circ} 033 / 2017$, oriundo do Executivo Municipal, que regulamenta $o$ uso de 
problemas com acompanhamento técnico para produzir; d) em Nova Esperança do Sul, 66,7\% queixaram-se da presença de doenças, pragas e ervas daninhas. Já em São Vicente do Sul, 66,7\% dos respondentes relataram sofrer com problemas tanto de mão de obra quanto com mercado incerto.

Todavia, para fazer frente as dificuldades próprias da olericultura e fruticultura, algumas organizações foram lembradas como defensoras e fomentadoras dessas atividades. Dentre essas, as com maior frequência citada pelos agricultores foram: a EMATER/ASCAR (citada por 212 agricultores $(86,5 \%)$ ) e as empresas de assistência técnica privada (citada por 73 agricultores respondentes $(29,8 \%))$.

\section{Os mercados acessados por agricultores familiares de flv do vale do jaguari}

Os mercados acessados pelos agricultores do Vale do Jaguari tanto de frutas quanto de hortaliças se mostram amplamente diversificados, com algumas particularidades para cada município. Em alguns casos, acontecem aqueles de proximidade, como as feiras locais de Santiago, Jaguari e São Vicente do Sul. Nesses, o tipo de agricultor é aquele produtor de excedente que comercializa de forma direta (quanto ao locus), havendo interpessoalidade e solidarismo na natureza das trocas, com base na confiança e na amizade no que diz respeito à regulação (Schneider, 2016).

Ainda, observam-se mercados convencionais, como o caso das melancias produzidas em Cacequi e São Francisco de Assis que viajam vários quilômetros para atender a demanda de outros estados do país. Nesses casos, o agricultor é considerado um produtor de mercadorias, onde as trocas não ocorrem em um local definido, predominando a concorrência (modelo de negócios), com regulações de contratos e preços, sendo que os canais de comercialização são ocupados por atravessadores (Schneider, 2016).

Quando observada a tabela 5, elucidativa do volume de alimentos comercializados em cada forma de mercado observa-se que ainda muitas são as potencialidades de abastecimento alimentar no Vale do Jaguari. Tal situação pode ser levada em consideração pela pequena quantidade de alimentos comercializados para os restaurantes, por exemplo. Além disso, mesmo que com maior representatividade para o caso das hortaliças, a quantidade de frutas com destino para redes de supermercados e pequenos e médios comércios ainda mostra resultados tênues. Nesse sentido, estudos demonstram que a dependência alimentar não se mostra unicamente para região deste estudo, mas também para o centro do estado como um todo (Dutra et al., 2017, Lamas, 2017). Isso, por sua vez, evidencia a dependência alimentar de FLV que o interior do Rio Grande do Sul possui em relação a outras regiões do país.

agroquímicos com um determinado princípio. Primeiramente, a proposta visa instituir um calendário que restrinja a aplicação no período de 15 de setembro a 15 de março para todos os anos subsequentes a data da lei, em área definida (zona de vitivinicultura do município). Já uma segunda regulamentação, diz respeito à proibição da aplicação de determinado herbicida via pulverização aérea (Câmara Municipal de Vereadores de Jaguari, 2017).
Mesmo diante dessa situação e considerando as manifestações de produção e comércio local, ao analisar a tabela 4 constata-se que tanto para caso das frutas quanto das hortaliças o canal de comercialização que predomina para os agricultores são as feiras livres, uma vez que pelo menos $15,81 \%$ das frutas e $24,95 \%$ das hortaliças são comercializadas por esse canal. Já quando analisados de maneira individual, o segundo e terceiro canal mais importantes para as frutas são a agroindustrialização no próprio estabelecimento rural (14,53\%), seguido pela opção "outros", com 14,46\% (essa última opção, devido a diversidade de respostas obtidas, optou-se por não tabulá-las). Todavia, constatou-se que grande parte dos respondentes que operam em "outros" canais estão relacionados à venda para intermediários da produção, como o caso, da venda das próprias melancias já citadas.

Mesmo que o abastecimento de frutas para redes de supermercados não seja uma realidade de todo Vale do Jaguari, em Cacequi quase um quarto (24,52\%) da produção desses alimentos é comercializado para redes de supermercados. Já em Jaguari, os mercados de maior comercialização de frutas são para cooperativas $(60,33 \%)$, visto que existe no município uma cooperativa tradicional no concernente ao beneficiamento da uva em vinhos e sucos.

Em Mata, as frutas em sua magnitude (30\%) são agroindustrializadas nos próprios estabelecimentos rurais e também comercializadas para agroindustrialização em outras propriedades (29\%). Inexistem entre os agricultores entrevistados os que comercializem para cooperativas, PAA, pequenos e médios comércios, e restaurantes.

Em Nova Esperança do Sul, do mesmo modo que em Mata, a maior parte das frutas também é beneficiada nas propriedades rurais (30,93\%). Também ganha destaque no município a comercialização de frutas nos próprios estabelecimentos rurais $(17,86 \%)$ e com entregas domiciliares $(14,29 \%)$. São inexpressivos no município o comércio para cooperativas, PAA e pontos de venda na estrada. Em São Francisco de Assis, a maior parte das frutas é comercializada em "outros" canais $(38,52 \%)$, seguido pela venda para pequenos e médios estabelecimentos $(18,57 \%)$ e agroindustrialização no próprio estabelecimento rural $(12,71 \%)$. Já os restaurantes, as feiras livres e as padarias e sorveterias do município não foram consideradas como ponto de vendas pelos produtores locais de frutas.

Em São Vicente do Sul, são reduzidos os mercados acessados pelos agricultores de frutas, sendo que os que mais ganham destaque são as feiras livres $(41,45 \%)$, as entregas domiciliares $(18,13 \%)$ e os mercados da alimentação escolar $(18,13 \%)$. Os demais não ocupam grande significância, sendo que muitos (redes de supermercados, restaurantes, padarias e sorveterias) nem são acessados.

Quando discutido o caso de Santiago, seguindo a tendência do Vale do Jaguari, a maior parte das frutas são comercializadas via feiras livres $(44,77 \%)$, uma vez que no município existe pelo menos quatro feiras livres funcionando diariamente com exceção dos domingos e uma feira específica de pêssego na temporada de safra. 
Tabela 5. Percentual de vendas de frutas e hortaliças do Vale do Jaguari por canal de comercialização. Fonte: Elaborado pelo autor com base nos dados primários (2017).

\begin{tabular}{lcc}
\hline & Frutas (\%) & Hortaliças (\%) \\
\hline Feira Livre & 15,81 & 24,95 \\
Cooperativa & 8,77 & 2,93 \\
Mercado Institucional da Alimentação Escolar & 5,65 & 9,60 \\
Mercado Institucional do PAA & 2,67 & 3,01 \\
Comercialização na propriedade & 8,41 & 12,86 \\
Vendas com entregas em domicílio & 9,00 & 8,25 \\
Pequeno e médio comércio & 6,82 & 18,01 \\
Redes de supermercados & 5,87 & 12,10 \\
Restaurante & 0,53 & 1,16 \\
Padaria e Sorveteria & 0,48 & 0,44 \\
Agroindustrializa na própria propriedade & 14,53 & 1,86 \\
Comercializa para agroindústrias & 5,34 & - \\
Ponto de venda na estrada & 1,66 & - \\
Outros & 14,46 & 4,81 \\
\hline
\end{tabular}

As vendas para restaurantes, padarias e o próprio beneficiamento das frutas mostram-se como mercados potenciais a serem explorados no município, visto que dentre os municípios do Vale do Jaguari este é o que possui maior contingente populacional, logo o maior efetivo de possíveis consumidores.

No que diz respeito ao comércio das hortaliças, verificase uma significativa representatividade das vendas através de feiras livres $(24,95 \%)$, para pequenos e médios comércios $(18,01 \%)$ e no próprio estabelecimento rural $(12,86 \%)$. Renting, Marsden e Banks (2003), chamam atenção que tais iniciativas de compra através de circuitos curtos de produção e comércio de alimentos destoam dos pressupostos do modelo convencional de agricultura. Além disso, acrescentam que a (re)afirmação desses circuitos alimentares fazem parte de uma gama de mudanças que vêm ocorrendo no sistema agroalimentar global, onde se têm consumidores cada vez mais preocupados com a segurança alimentar, saúde e ecologia.

$\mathrm{Em}$ Cacequi, os pequenos e médios comércios mostram-se acessíveis para compra de hortaliças de agricultores locais, visto que $49,27 \%$ desses alimentos são comercializados nesses espaços. Todavia, nem os mercados institucionais nem o comércio nos próprios estabelecimentos rurais são destacados entre as principais formas de venda da produção do município. No que diz respeito ao comércio em feiras livres, a maior parte das hortaliças de Jaguari $(25,00 \%)$ são comercializadas nesses mercados, seguido pelo comércio por cooperativas $(17,78 \%)$ e na propriedade $(14,44 \%)$.

A comercialização de hortaliças na propriedade ganha destaque também no município da Mata e em Nova Esperança do Sul, sendo que $28,60 \%$ e $27,50 \%$, respectivamente, da produção são comercializados nesses mercados. Ainda na cidade de Mata, a feira livre representa uma importante oportunidade de comércio, sendo que $22 \%$ das hortaliças são vendidas por meio desse canal. Já em Nova Esperança do Sul, o mercado institucional da alimentação escolar $(26,75 \%)$ e as entregas domiciliares $(18,33 \%)$ são outros canais relevantes no que tange o comércio de hortaliças. Para ambos os municípios, os mercados do PAA e a presença de cooperativas para venda de hortaliças mostram-se inexpressivos.

São Francisco de Assis é um município abastecedor de redes de supermercados no que diz respeito as hortaliças, sendo que $41,36 \%$ da sua produção possui como destino esses canais. Todavia, ainda mostram-se pouco relevantes as iniciativas de compra pelos restaurantes do município.

Quanto às feiras livres, essas demonstram suma importância para a venda de hortaliças tanto de São Vicente do Sul $(39,00 \%$ da produção) quanto de Santiago (54,12\%). Em São Vicente do Sul, os pequenos e médios comércios também são responsáveis pela compra de grande parte da produção $(25,00 \%)$ local. Os programas institucionais, por sua vez, juntos absorvem pelo menos um quarto de toda produção de olerícolas do município. Já em Santiago, os supermercados $(9,82 \%)$ e os pequenos e médios comércios $(8,46 \%)$ também se mostram sensitivos a compra local. Todavia, em ambos os municípios as vendas para restaurantes ainda podem ser potencializadas.

$\mathrm{Na}$ tentativa de adaptar os percentuais de quanto de frutas e hortaliças são comercializados em cada mercado, em conformidade à proposição teórica de Schneider (2016), elaborou-se a tabela 5.

A Tabela 6 mostra que $49,4 \%$ das frutas e $47,9 \%$ das hortaliças são comercializadas em mercados de proximidade. Para o caso das frutas, além do significativo montante vendido em feiras livres, o beneficiamento das frutas nos próprios estabelecimentos rurais também corrobora para essa classificação. Esse processo de beneficiamento das frutas em municípios do Vale do Jaguari pelos próprios agricultores e, principalmente, da uva também já foi constatado em outros estudos (Brasil, 2016, Silva, 2016, Silveira, 2013).

No que diz respeito aos mercados territoriais, se observa uma superioridade no volume comercializado de hortaliças em relação às frutas. 
Tabela 6. Mercados acessados por agricultores de FLVs do Vale do Jaguari e sua aproximação com a tipologia proposta. Fonte: Elaborado com base nos dados primários e com base em Schneider (2016).

\begin{tabular}{|c|c|c|c|c|c|}
\hline & & \multicolumn{2}{|c|}{ Frutas (\%) } & \multicolumn{2}{|c|}{ Hortaliças (\%) } \\
\hline & & $\begin{array}{c}\% \text { por } \\
\text { mercado }\end{array}$ & $\begin{array}{c}\% \\
\text { total }\end{array}$ & $\begin{array}{c}\% \text { por } \\
\text { mercado }\end{array}$ & $\begin{array}{c}\% \\
\text { total }\end{array}$ \\
\hline \multirow{5}{*}{$\begin{array}{l}\text { Mercados de } \\
\text { proximidade }\end{array}$} & Feira livre & 15,81 & \multirow{4}{*}{49,41} & 24,95 & \multirow{5}{*}{47,92} \\
\hline & Comercialização na propriedade & 8,41 & & 12,86 & \\
\hline & $\begin{array}{c}\begin{array}{c}\text { Vendas com entregas em } \\
\text { domicílio }\end{array}\end{array}$ & 9,00 & & 8,25 & \\
\hline & $\begin{array}{l}\text { Agroindustrializa na própria } \\
\text { propriedade }\end{array}$ & 14,53 & & 1,86 & \\
\hline & Ponto de venda na estrada & 1,66 & & 0 & \\
\hline \multirow{3}{*}{$\begin{array}{l}\text { Mercados locais e } \\
\text { territoriais }\end{array}$} & Pequeno e médio comércio & 6,82 & \multirow{3}{*}{7,83} & 18,01 & \multirow{3}{*}{19,61} \\
\hline & Restaurante & 0,53 & & 1,16 & \\
\hline & Padaria e Sorveteria & 0,48 & & 0,44 & \\
\hline \multirow{3}{*}{$\begin{array}{l}\text { Mercados } \\
\text { Convencionais }\end{array}$} & Cooperativas & 8,77 & \multirow{3}{*}{19,98} & 2,93 & \multirow{3}{*}{15,03} \\
\hline & Redes de supermercados & 5,87 & & 12,1 & \\
\hline & $\begin{array}{l}\text { Comercializa para } \\
\text { agroindústrias }\end{array}$ & 5,34 & & 0 & \\
\hline \multirow{2}{*}{$\begin{array}{l}\text { Mercados } \\
\text { institucionais }\end{array}$} & $\begin{array}{l}\text { Mercado Institucional da } \\
\text { Alimentação Escolar }\end{array}$ & 5,65 & \multirow[t]{2}{*}{8,32} & 9,6 & \multirow[t]{2}{*}{12,61} \\
\hline & Mercado Institucional do PAA & 2,67 & & 3,01 & \\
\hline
\end{tabular}

Tais resultados, podem estar relacionados a maior facilidade que as hortaliças produzidas no Vale possuem frente à comercialização de frutas nos pequenos e médios estabelecimentos comerciais. As frutas são comercializadas majoritariamente nos mercados convencionais, para uma cooperativa beneficiadora existente no município de Jaguari.

Por fim, por mais que haja disparidade entre os valores encontrados para a quantidade de frutas e hortaliças comercializadas para os mercados institucionais ambos absorvem uma parte importante do que se é produzido de frutas e hortaliças na região. Resultados mais precisos demandariam estudos em que se confrontassem dados da capacidade de compras de produtos locais e a quantidade que está sendo comprada atualmente, o que não é objetivo desta pesquisa. Assim, ressalta-se que tanto a tabela 4 quanto da 5 relacionam ao total de frutas e hortaliças produzidas no Vale do Jaguari absorvidas por cada tipo de mercado, não entrando no mérito se as compras institucionais mostram-se adequadas ou não.

\section{CONSIDERAÇÕES FINAIS}

Nesta pesquisa exploraram-se as particularidades dos mercados acessados por agricultores familiares produtores de frutas, legumes e verduras. Para tanto, caracterizou-se os produtores rurais, os estabelecimentos agropecuários, bem como os processos de produção e comercialização dos referidos alimentos na região do Vale do Jaguari. Em um primeiro momento, acreditava-se que não eram muitas as experiências bem sucedidas de produção e comercialização local de alimentos, sendo restritas a experiências tradicionais e já conhecidas na região como da uva em Jaguari, da melancia em Cacequi e da batata doce em São Vicente do Sul. Todavia, ao longo das etapas da pesquisa constatou-se que mesmo diante das dificuldades próprias da fruticultura e da olericultura existem outras manifestações produtivas que logram êxito, tais como o abastecimento local pelas feiras livres, o comércio nos próprios estabelecimentos rurais, bem como o aprovisionamento de pequenos e médios comércios.

Dentro dessa perspectiva, considerações de cunho mais geral, mas intimamente ligadas ao referencial teórico da pesquisa merecem ser destacados. Os mercados de proximidade, elencados por Schneider (2016), onde se tem um locus específico no momento das trocas e os limites físicos dos mercados são facilmente identificáveis, concomitantemente com regulações baseadas em relações de confiança, predominam frente a outros mercados do Vale do Jaguari. Tal predominância corrobora com a ideia de que, em específico, no sistema agroalimentar não são apenas as forças convencionais de mercado (oferta e demanda) que regem o quanto se é comercializado, mas também existem valores ligados a interpessoalidade das trocas, a confiança depositada no ofertante do alimento a ser comercializado, bem como fatores ligados a própria paisagem, seja ela influenciada pela compra direta na propriedade, da rotina das feiras livres ou outros fatores próprios desses mercados.

Não menos importante é a verificação de que os mercados locais e territoriais são amplamente acessados pelos fruticultores e olericultores, onde ainda se conhecem as delimitações geográficas e ao agricultor é depositado certo grau de confiança. Tais mercados ganham relevância muito em função da facilidade de compra junto ao agricultor, uma vez que ainda se está tratando de locus definido que circunscreve os municípios ou região. Além do mais, destaca-se que a reputação atribuída ao agricultor dispensa contratatos para que ocorram negociações. 
Tal motivo justifica que grande parte dos negócios desses mercados ocorram junto a menores comércios, onde, por vezes, as formalidades são dispensadas. $O$ beneficiamento das frutas ocupa posição de destaque na região analisada, junto à compra de hortaliças por redes de supermercados.

Já quanto aos mercados institucionais, onde há exigência de contratos públicos e o cumprimento de leis específicas também se mostrou como destino das frutas produzidas localmente, mas principalmente das hortaliças. Para ambos os casos, o mercado da alimentação escolar ocupou maior importância quando comparado ao PAA, possivelmente em razão do número de beneficiários do primeiro ser superior ao do segundo.

Com relação ao perfil do atual agricultor que produz frutas e hortaliças, foi verificado que a média de idade desses atores para o Vale do Jaguari é superior a cinquenta anos. Além do envelhecimento dos produtores envolvidos nesses cultivos, verifica-se um fenômeno de "esvaziamento" do campo, uma vez praticamente um quarto das propriedades visitadas apresentaram apenas dois residentes (um casal de agricultores). Essa dinâmica, muitas vezes acaba por mudar o modus operandi do agricultor, surgindo então agricultores especializados em poucos cultivos.

Verificou-se um consenso na percepção das potencialidades da produção de FLV com fins comerciais. Todavia, a falta de apoio governamental, a dificuldade no acompanhamento técnico e má conservação das estradas, ainda são lembrados como gargalos que afetam às decisões de permanência nestas atividades. Tal resultado denota à necessidade premente de ações mais incisivas dos gestores locais e do poder público. Ademais, as discussões acerca da importância da fruticultura e olericultura da região devem ser analisadas no contexto das novas demandas, decorrentes do aumento da reflexividade por parte dos consumidores sobre a qualidade daquilo que se consome.

\section{REFERÊNCIAS}

Agne, C. L. \& P. D. Waquil. 2011. A rede de relações sociais nos mercados de proximidade: os canais de comercialização e troca das agroindústrias rurais familiares da região do Corede Jacuí Centro-RS. Ensaios FEE 31:779-806.

Alves, F. D. \& V. C. P. Silveira. 2008. Evolução das desigualdades regionais no Rio Grande do Sul: espaço agrário, imigração e estrutura fundiária. Caminhos de Geografia 9: 1-15.

Anése, R. L. R. 2009. Arranjos Produtivos Locais e Capital Social no Vale do Jaguari/RS. D.r. Tese. Universidade Federal do Rio Grande do Sul, Porto Alegre/RS.

$123 \mathrm{pp}$.

Bertê, A. M. A., B. O. Lemos, G. Testa, M. A. R.

Zanella \& S. B. Oliveira, 2016. Perfil socioeconômico Corede Vale do Jaguari. Boletim Geográfico do Rio Grande do Sul 26: 909-941.

Brasil, C. R. B. 2016. Agricultores familiares pluriativos na região do Vale do Jaguari/RS: um estudo em Nova Esperança do Sul. M. Sc. Dissertação. Universidade
Federal do Rio Grande do Sul, Porto Alegre/RS. 136 pp.

Bowen, S. 2010. Embedding Local Places in Global Spaces: Geographical Indications as a Territorial Development Strategy. Rural Sociology 75: 209 - 243.

Câmara Municipal de vereadores de Jaguari. 2017. Câmara municipal aprova projeto de lei para uso de princípio ativo 2,4-D. 2017. Disponível em: < http://camara.jaguari.rs.gov.br/2017/07/camara-

municipal-aprova-projeto-de-lei-para-uso-de-principioativo-24-d/>. Último acesso: agosto de 2018.

Cesar, G. 1979. História do Rio Grande do Sul. Período Colonial. Editora do Brasil, São Paulo. 327 pp.

CMS - Civil society mechanism. 2017. Connecting smallholders to markets. Disponível em: < https://handsontheland.net/wp-

content/uploads/2016/10/CONNECTING-

SMALLHOLDERS-TO-MARKET-english.pdf>. Último acesso: agosto de 2018.

Coley, D. A., M. Howard \& M. Winter. 2011. Food miles: time for a re-think? British Food Journal 113: 919934.

Costa, J. P., L. M. Rimkus \& B. P. Reydon. 2008. Agricultura familiar, tentativas e estratégias para assegurar um mercado e uma renda. In: Congresso da sociedade brasileira de economia, administração e sociologia e rural, XLVI., 2008, Rio Branco/AC. Anais... Rio Branco/AC: SOBER.

Craviotti, C. 2013. La agricultura familiar en los mercados globales: Articulación horizontal y vertical en la citricultura del Noreste Argentino. In: Mercados e agricultura familiar: interfaces, conexões e conflitos. Conterato, MA, Niederle, PA, Triches, RM, Marques, FC, Schultz, G. (Coordenadores). Ed. Via Sapiens, Porto Alegre. pp. 19-35.

Cunha, A. R. A. A. \& Belik, W. 2012. A produção agrícola e a atuação das Centrais de Abastecimento no Brasil. Segurança Alimentar e Nutricional 19: 46-59.

Cunha, A. R. A. A. 2015. Dimensionando "o passeio das mercadorias". Uma análise através dos dados do Prohort. Revista de Política Agrícola 4: 55-63.

Dutra, E. G., G. P. Silva \& H. D. Zen. 2017. Origens e razões do desabastecimento alimentar de frutas, legumes e verduras da Região Central do Rio Grande do Sul. In: Congresso da sociedade brasileira de economia, administração e sociologia e rural, 55., 2017, Santa Maria/RS. Anais... Santa Maria/RS: SOBER, 2017.

FEE - Fundação de economia e estatística. 2016. FEE Dados. Perfil Socioeconômico. Disponível em: < https://www.fee.rs.gov.br/indicadores/indice-de-

desenvolvimento-socioeconomico/>. Último acesso: agosto de 2018.

FEE - Fundação de economia e estatística. FEE Dados. 2015. Território. Disponível em: < http://feedados.fee.tche.br/feedados/\#!pesquisa=0>. Último acesso: agosto de 2018.

Froehlich, J. M., C. C. Rauber, R. H Carpes, \& M. Toebe. 2011. Exxodo seletivo, masculinização e envelhecimento da população rural na região central do RS. Ciência Rural 41: 1674-1680.

Gil, A. C. 2009. Como elaborar projetos de pesquisa. Atlas, São Paulo: 200 pp. 
Giovanini, A., S. R. Marin, C. Ataídes \& M. Arend. 2011. Estrutura fundiária e Desenvolvimento Humano: uma análise para as microrregiões do Rio Grande do Sul. Estudos do CEPE 34: 263-290.

Grisa, C., C. J. Schimitt, L. F. Mattei, R. S. Maluf \& S. P. Leite. 2011. Contribuições do Programa de Aquisição de Alimentos à segurança alimentar e nutricional e à criação de mercados para a agricultura familiar. Agriculturas 8: 34-41.

IBGE - Instituto brasileiro de geografia e estatística. 2006. Censo Agropecuário 2006. Disponível em: <https://ww2.ibge.gov.br/home/estatistica/economia/agr opecuaria/censoagro/default.shtm>. Último acesso: agosto de 2018.

IBGE - Instituto brasileiro de geografia e estatística. 2010. Censo Demográfico 2010. Disponível em: < https://ww2.ibge.gov.br/home/estatistica/populacao/cen so2010/>. Último acesso: agosto de 2018.

Ilha, A. S. \& G. T. Molinari. 2008. Avaliação dos setores potenciais e estagnados da microrregião do Vale do Jaguari para o período 1990-2005. In: Encontro de economia gaúcha, 4., 2008, Porto Alegre/RS. Anais... Porto Alegre/RS: Pontifícia Universidade Católica do Rio Grande do Sul.

Kirwan, J. 2004. Alternative Strategies in the UK AgroFood System: Interrogating the Alterity of Farmers' Markets. Sociologia Ruralis 44: $395-415$.

Lamas, J. P. 2017. Santa Maria produz 10 vezes menos do que consome. Diário de Santa Maria, Santa Maria: 8-9.

Lazzarotto, D. 1976. História do Rio grande do Sul. Ed. Sulina, Porto Alegre. $154 \mathrm{pp}$.

Maluf, R. S. 2004. Mercados agroalimentares e a agricultura familiar no Brasil: agregação de valor, cadeias integradas e circuitos regionais. Ensaios FEE 25: 299-322.

Marsden, T. K \& J. S. B. Cavalcanti. 2001. Globalisation, sustainability and the new agrarian regions: food, labour and environmental values. Cadernos de Ciência \& Tecnologia 18: 39-68.

Morais. E. P. 2007. Envelhecimento no meio rural: condições de vida, saúde, e apoio dos idosos mais velhos de Encruzilhada do Sul - RS. D.r. Tese. Universidade de São Paulo, Ribeirão Preto/SP. 210 pp.

Niederle, P. A. 2016. Mercados como arenas de luta por reconhecimento: disputas morais na construção dos dispositivos de qualificação dos alimentos. Política \& Sociedade 15: 97-130.

Paula, S. B. 1999. A colonização italiana e a reestruturação agrária da região centro-oeste. M. Sc. Dissertação. Universidade Federal de Santa Maria, Santa Maria. 138 pp.

Perez-Cassarino, J \& A. D. D. Ferreira. 2013. A construção de mecanismos alternativos de mercados de alimentos ecológicos como forma de redesenhar os sistemas agroalimentares: a proposta dos circuitos de proximidade. In: Congresso internacional sistemas agroalimentares localizados, VI,. 2013, Florianópolis/SC. Anais... Florianópolis: UFSC.

Ploeg, J. D. V. 2006. O modo de produção camponês revisitado. In: A diversidade da agricultura familiar. Schneider, S. Editora da UFRGS, Porto Alegre. pp. 1354.

Ploeg, J. D. V. 2008. Camponeses e impérios alimentares: lutas por autonomia e sustentabilidade na era da Globalização. Editora da UFRGS, Porto Alegre. $372 \mathrm{pp}$.

Ploeg, J. D. V., Y. Jingzhong \& S. Schneider. 2012. Rural development through the construction of new, nested, markets: comparative perspectives from China, Brazil and the European Union. Journal of Peasant Studies 39: $133-173$.

Reardon, T., C. P. Timmer, C. B. Barrett \& J. Berdegué. 2003. The rise of supermarkets in Africa, Asia, and Latin America. American journal of agricultural economics 85: 1140-1146.

Renting, H., T. K. Marsden \& J. Banks. 2003. Understanding alternative food networks: exploring the role of short food supply chains in rural development. Environment and Planning A: Economy and Space 35: 393-411.

Roche, J. 1969. A colonização alemã e o Rio Grande do Sul. Globo, Porto Alegre. 401 pp.

Sangoi, D. S. 2006. Mapeamento geoambiental da bacia hidrográfica do Arroio Inhacundá, município de São Francisco de Assis/RS. M. Sc. Dissertação. Universidade Federal de Santa Maria, Santa Maria/RS. $75 \mathrm{pp}$.

Schneider, S. 2016. Agricultura Familiar e Mercados. In: Construção de Mercados e Agricultura Familiar: Desafios para o Desenvolvimento Rural. Marques, F.C., Conterato, M.A. \& Schneider, S, Ed. da UFRGS, Porto Alegre pp. 93-140.

Schneider, S., N. Salvate \& A. Cassol. 2016. Nested markets, food networks, and new pathways for rural development in Brazil. Agriculture 6: 61-80.

Schumacher, E. F. 1983. O negócio é ser pequeno. Um estudo de economia que leva em conta as pessoas. Ed. Zahar, Rio de Janeiro. 317 pp.

Silva, G. P. 2016. A construção social dos circuitos curtos de comercialização e consumo de alimentos: a emergência de novas institucionalidades. D.r. Tese. Universidade Federal de Santa Maria, Santa Maria/RS. $273 \mathrm{pp}$.

Silva, R.B. \& R. L. R. Anése. 2011. O Vale do Jaguari RS: desafios e perspectivas. In: Experiências de desenvolvimento local do Vale do Jaguari e Região Central - Campus São Vicente do Sul. Dorneles, S.B., Silva, G.P. \& Deon, P.R .C. (coordenadores).

Ed. IFFar Campus São Vicente do Sul. São Vicente do Sul/RS. pp: 20-30.

Silveira, L.B. 2013. Agricultura familiar e informalidade: o seu papel no abastecimento local de alimentos. D.r. Tese. Universidade Federal de Santa Maria, Santa Maria/RS. 202 pp.

Sonnino, R. \& T. Marsden. 2006. Beyond the divide: rethinking relationships between alternative and conventional food networks in Europe. Journal of Economic Geography 6: 181-199.

Souza, M.S. 2009. Redes de cooperação no pequeno varejo: a construção social dos mercados de hortifrutigranjeiros no Rio Grande do Sul. D.r. Tese. Universidade Federal do Rio Grande do Sul, Porto Alegre/RS, 308 pp.

Thorsoe, M. \& E. Noe. 2016. Cultivating market relations-Diversification in the Danish organic production sector following market expansion. Sociologia Ruralis 56: 331-348, 2016. 
Revista de la Facultad de Agronomía, La Plata (2019) Vol 118 (1): 147-159

Uberti, H.G. 2012. O Vale do Jaguari no processo de construção da fronteira oeste do Rio Grande do Sul. Revista Eletrônica História em Reflexão 6: 1-19.

Vendruscolo, R., Cruz, F. T. \& Schineider, S. 2016.

$(\mathrm{Re})$ Valorización de los alimentos de la agricultura familiar: límites y particularidades de las estrategias agroalimentarias en el estado de Rio Grande do Sul, Brasil. Agroalimentaria 22: 149-169.

Wilkinson, J. 2004. A Agricultura Familiar ante o Novo
Padrão de Competitividade do Sistema Agroalimentar na América Latina. Estudos Sociedade e Agricultura 1: 62-87.

Wilkinson, J. 2008. Mercados, redes e valores. Editora da UFRGS, Porto Alegre. 213 pp.

Wiskerke, J. S. C. 2009. On Places Lost and Places Regained: Reflections on the Alternative Food Geography and Sustainable Regional Development. International Planning Studies 14: 369 - 387. 